\title{
Epigenetic self-regulation of developmental excision of an internal eliminated sequence in Paramecium tetraurelia
}

\author{
Sandra Duharcourt, Alain Butler, and Eric Meyer ${ }^{1}$ \\ Laboratoire de Génétique Moléculaire, URA1302, Ecole Normale Supérieure, 75005 Paris, France
}

\begin{abstract}
Differentiation of the somatic macronucleus of ciliates after sexual events involves the programmed excision of thousands of single-copy internal eliminated sequences (IESs) from the germ-line genome. We have studied two cell lines of Paramecium tetraurelia that have identical germ-line genomes but differ in their macronuclear genomes. In the IES - cell line, a 222-bp IES interrupting a coding sequence is reproducibly excised during macronuclear differentiation, whereas it is not in the IES + cell line. In a cross between the two lines, the developmental alternative is maternally inherited, suggesting that it is epigenetically controlled by the old (prezygotic) macronucleus in each cell. Transformation of the macronucleus of both lines with plasmids carrying fragments of either version of the gene shows that the presence of the IES sequence in the old macronucleus results in retention of the IES in the new macronuclear genome of sexual progeny. This could be attributable to (1) inhibition of excision, or (2) repair of a double-strand gap left in the genomic sequence after constitutive excision of the IES, by a polymerization mechanism using a homologous IES + template from the old macronucleus. The latter possibility is ruled out by experiments showing that modified IESs can inhibit excision without being copied in the new macronuclear genome. Possible mechanisms are discussed in the light of a quantitative analysis of excision inhibition by the maternal IES sequence.
\end{abstract}

[Key Words: Genomic rearrangements; IES excision; maternal inheritance; macronuclear differentiation; ciliates]

Received May 23, 1995; revised version accepted June 30, 1995.

Alternative DNA rearrangements have been shown to play a role in the developmental regulation of gene expression in a broad range of organisms but only in isolated cases, such as sporulation in Bacillus subtilis, mating-type switching in yeast, or the generation of immunoglobulin diversity in vertebrates. In no other group of organisms have programmed genomic rearrangements become such common practice as in the ciliates. The unique nuclear dimorphism characterizing these unicellular eukaryotes allows them to keep copies of the germline genome in the transcriptionally silent micronuclei, for use in sexual events (meiosis and fertilization), while expressing their genes from the extensively rearranged version of the genome found in the macronuclei. Macronuclei are highly polyploid somatic nuclei that divide amitotically and are destroyed at the end of the vegetative phase of the life cycle, during sexual events; after fertilization, new macronuclei and micronuclei differentiate from mitotic products of the zygotic nucleus. In addition to the amplification of the genome, the differ-

${ }^{1}$ Corresponding author. entiation of a macronucleus from a diploid nucleus involves two types of reproducible rearrangements: the fragmentation of germ-line chromosomes in specific regions, followed by the addition of new telomeres, and the elimination of numerous internal sequences, either single-copy or repetitive, from most genes (for review, see Prescott 1994). This complete developmental remodeling of the genome could be used by ciliates to produce functionally diverse vegetative clones from a given germ-line genotype and maintain useful polymorphisms. This would require the capacity to regulate specifically individual rearrangements.

The study of Paramecium strains with entirely homozygous germ-line genomes has revealed that an epigenetic, sequence-specific mechanism is involved in the developmental choice of alternative telomere addition regions in at least three events of germ-line chromosome fragmentation. These alternative rearrangements can lead to the loss from the somatic genome of genes normally located near macronuclear telomeres (Meyer 1992; Kim et al. 1994; Scott et al. 1994a) or to the modulation of their expression (Keller et al. 1992). Specific regulation may also occur for the other type of developmental ge- 
nomic rearrangements identified in Paramecium, the removal of single-copy internal eliminated sequences (IESs) from the germ-line genome. IESs are short (28-882 bpl, AT-rich sequence elements that appear to be noncoding. During macronuclear differentiation, they are excised precisely between two 5'-TA-3' direct repeats, one copy of which is left in the macronuclear sequence. As in other ciliates, the number of IESs in the genome is probably quite high. Thirteen have been found in the coding sequences and flanking regions of two surface antigen genes, totaling $20 \mathrm{~kb}$ (Steele et al. 1994; Scott et al. 1994b); if these examples are representative, there could be as many as 65,000 IESs per haploid genome. Such a widespread occurrence, similar to that of introns in nuclear genes of some eukaryotes, suggests that most IESs are excised by a common molecular machinery, about which little is known. A statistical analysis of the sequence of IES ends has revealed nonrandom base frequencies at some positions within the first and last 20 bp. The reconstituted palindromic consensus sequence shows similarity to the ends of the inverted repeats of transposons of the Tc1/mariner family, which suggests that present-day IESs derive from ancestral integrations of such transposons (E. Meyer, unpubl.; Klobutcher and Herrick 1995). High-copy transposon-like elements identified in the germ-line genome of several other ciliates are recognizable members of this family (Doak et al. 1994). In Euplotes crassus, developmental excision of both transposon-like elements and single-copy IESs generates free circular forms with an unusual heteroduplex covalent junction (Jaraczewski and Jahn 1993; Klobutcher et al. 1993).

Some evidence of specific regulation of IES excision was obtained in the study of a Mendelian mutant of Paramecium tetraurelia, $m t F^{E}$. This pleiotropic mutation affects macronuclear differentiation, resulting in the developmental determination of a variety of mutant phenotypic characters (Brygoo and Keller 1981a), and in constitutive determination for one of two alternative mating types (Brygoo and Keller 1981b). It was shown further to affect the developmental excision of a 222-bp IES interrupting the coding sequence of the $G$ gene, a non-essential gene encoding one of several alternative surface antigens (E. Meyer and A.-M. Keller, in prep.). The G-gene IES is thus maintained in the macronuclear genome of the $m t F^{E}$ strain. Surprisingly, it was observed that when the $m t F^{E}$ allele of the mutant cell line is replaced genetically by the wild-type $m t F^{+}$allele, the developmental excision of this IES is not restored in the cytoplasmic descent of the mutant cell, even after many successive autogamies (self-fertilization sexual cycles) of $m t F^{+}$homozygotes. A new cell line is thus produced that never excises the $G$-gene IES from its macronuclear genome (hereafter referred to as the IES + line), although its germ-line genome is supposed to be identical to that of the wild-type strain, which regularly excises the IES during macronuclear differentiation (the IES - line).

In this work we have investigated the basis for the heritable difference between the IES + and IES - lines. We show that like mating types or alternative chromo- some fragmentation patterns, the excision and nonexcision characters follow a maternal pattern of inheritance in crosses between the IES + and IES - lines, confirming that the developmental alternative is controlled by the old macronucleus in each cell and does not depend on any germ-line difference. Transformation of the vegetative macronucleus of both lines by plasmids containing fragments of the $G$ gene shows that during nuclear reorganization, the presence of the IES sequence itself in the old macronucleus inhibits its own excision in the developing macronucleus.

\section{Results}

Maternal inheritance of the IES + and IES characters at conjugation

To study the inheritance of the IES + and IES - developmental alternatives during conjugation, an IES + clone of mating type $E$ was crossed with an IES - clone of mating type $O$. After the pairing of the cells, the micronuclei undergo meiosis. An additional mitosis of the single surviving meiotic product yields two identical haploid gametic nuclei in each cell. The two paired cells then exchange one of these nuclei; karyogamy thus results in the formation of genetically identical $F_{1}$ zygotic nuclei in the two mates (Sonneborn 1974). If the IES + and IES - characters were determined genetically in the zygotic nucleus, the phenotype of the $F_{1}$ macronucleus would be the same in the progeny of both mates.

Three pairs were analyzed. After their separation, the two exconjugants from each pair were isolated. Each exconjugant produces two $F_{1}$ caryonides (after two divisions of the zygotic nucleus, two of the products differentiate into new macronuclei, which segregate without division to the two daughter cells); one of the two from each exconjugant was cultivated. The maternal inheritance of mating types in $P$. tetraurelia provides an independent means to identify the parental origin of the $F_{1}$ caryonides (see Materials and methods). Figure 1 shows a

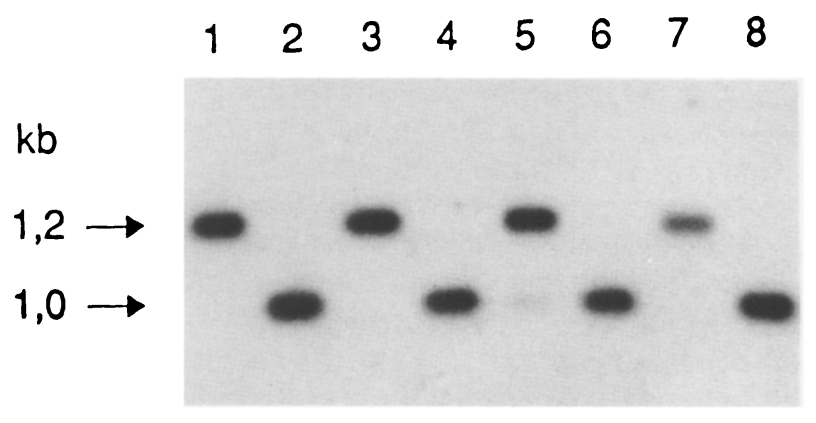

Figure 1. Southern blot analysis of a cross between IES + and IES - cell lines. Total DNA was digested with PstI, and the blot was hybridized with probe b (see Fig. 2). (Lane 1) The IES + parent; (lane 2) the IES - parent. (Lanes 3,5,7) $F_{1}$ caryonides derived from the IES + parents of three different pairs; (lanes 4,6,8) $F_{1}$ caryonides derived from the IES - parents of the same pairs. 
Southern blot of PstI-digested DNA from the IES + and IES - parents of the cross (lanes 1 and 2, respectively) and from the $\mathrm{F}_{1}$ caryonides (lanes 3-8). In the IES + macronuclear version of the $G$ gene, the IES is contained in a 1.2-kb Pst I fragment (see map in Fig. 2); the corresponding fragment of the IES - version is only $1 \mathrm{~kb}$ long. Only macronuclear DNA can be detected on such a blot, because it is $\sim 250$ times more abundant than micronuclear DNA. Hybridization of the blot with a probe specific for this fragment (see Fig. 2, probe b) shows that the three $F_{1}$ caryonides derived from the IES + parents are IES + themselves (lanes 3,5,7), whereas the three $F_{1}$ caryonides derived from the IES - parents are IES - (lanes 4,6,8). A small amount of the IES - form is detectable in the IES + caryonide 5 , as is sometimes observed in individual IES + caryonides obtained through autogamy). Thus, although conjugation yields identical germ-line genomes in all $F_{1}$ caryonides, in each one developmental processing of this genome produces the same macronuclear $G$-gene structure as in its cytoplasmic parent. The alternative processing therefore cannot be determined genetically in the zygotic nucleus. Rather, it appears to be controlled epigenetically by the old macronucleus in each cell.

Transformation of the IES + macronucleus with an IES - plasmid does not restore developmental excision after autogamy

The maternal inheritance of the IES + and IES - macronuclear versions may indicate that the mechanism of developmental excision is inhibited by the IES + old macronucleus or that it requires positive activation by the IES - old macronucleus. Alternatively, it is possible that excision occurs constitutively during development in both lines, leaving double-strand breaks in the G-gene coding sequence, at both junctions with the IES. Repair of the genomic sequence by polymerization, using a homologous template originating from the old macronucleus, would result in the copying of the maternal $G$-gene version. This "cut-and-repair" model is similar to the mechanisms involved in the repair of genomic sequences after excision of the P element in Drosophila (Engels et al. 1990) and the Tc1 transposon in Caenorhabditis (Plasterk 1991). It could account both for precise excision in IES - cells, and for the apparent lack of excision of one particular IES in genetically wild-type IES + cells, which presumably contain all trans-acting factors necessary for IES excision. Although the transfer of sequences from the old macronucleus to the developing one has not been demonstrated, such a process has been postulated previously to account for other effects of transforming plasmids on developmental rearrangements (see Discussion). To test this hypothesis, we first asked whether transformation of the vegetative macronucleus of IES + cells by a plasmid containing a portion of the IES - macronuclear version of the $G$ gene would promote excision in the postautogamous progeny of transformed clones. The plasmid, p629, contains a 629bp PstI-SpeI fragment located in the central part of the $\sim 8$-kb coding sequence (Fig. 2). An Asp718 site located 150 bp downstream from the PstI site is created by the excision of the 222-bp IES (Fig. 2). Plasmid p851, which
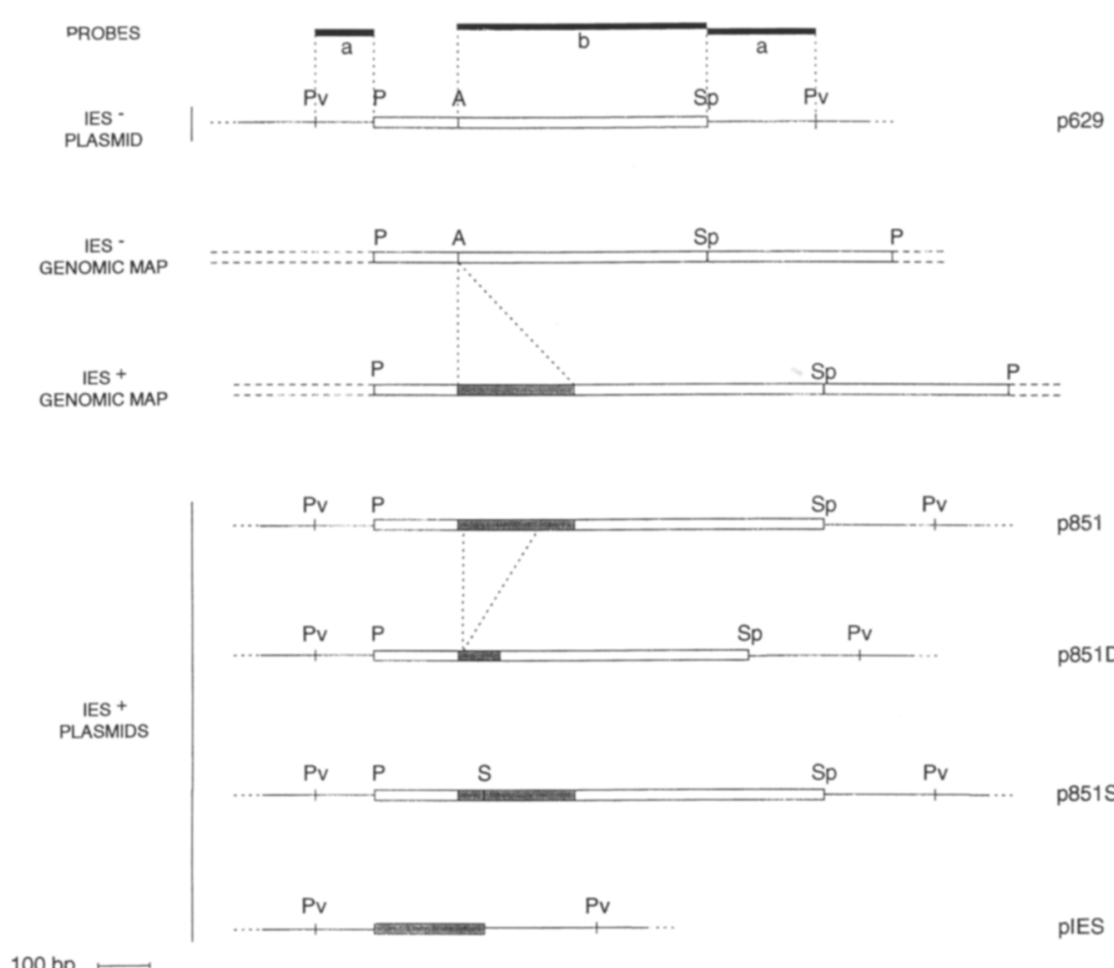

Figure 2. Restriction maps of the IES and IES + genomic sequences, and of the derived IES - and IES + plasmids. The positions of probes $a$ and $b$ are indicated at top. The IES is shown as a shaded box. In the plasmid maps, the thin line represents the pUC18 vector sequence. The restriction site abbreviations are (A) $A s p 718 ;(\mathrm{P})$ PstI; (Pv) PvuII; (S) SalI; (Sp) SpeI. 
contains the 851-bp IES + version of the same fragment, was used as a control. To minimize the nonhomologous recombination observed between monomers after microinjection of circular molecules into the macronucleus, the plasmids were linearized with a restriction enzyme cutting once in the pUC18 vector (when linear molecules are microinjected into the macronucleus, telomeric repeats are added to the extremities of monomers or end-to-end multimers; the resulting minichromosomes replicate autonomously during vegetative growth|. Injected cells were grown individually for eight to nine fissions; four clones containing various amounts of each plasmid, as well as two uninjected controls, were then selected by a quick dot-blot procedure (see Materials and methods) and cultivated further for DNA extraction and Southern blot analysis. Figure 3A shows a BglII digest of these samples, hybridized with probe $b$. The BglII fragment containing the endogenous IES + macronuclear $G$ gene is seen as a thin band near the top of each lane. Neither plasmid contains any BglII site; free-replicating monomers show up as somewhat smeared bands migrating at $3.5 \mathrm{~kb}$ (p629, lanes 1-4) or $3.7 \mathrm{~kb}$ (p851, lanes 5-8). Dimers give a band at $\sim 7 \mathrm{~kb}$. Plasmid copy numbers ranged from $<1$ per haploid genome (undetectable in clones 1 and 5 ; cf. with uninjected controls, lanes 9 and 10 ) to $>100$ copies per haploid genome in clones 4 and 8 (i.e., 100,000 copies per macronucleus; see the quantitative analysis section|. Lane 11 is an IES - wildtype control.

At the time of DNA extraction, $\sim 1000$ cells from each transformed clone were saved and starved to induce autogamy. In this self-fertilization process, the two identical gametic nuclei produced in each cell fuse together, yielding an entirely homozygous zygotic nucleus. Autogamy was checked by staining 100 cells from each clone to verify the fragmentation of the old macronucleus. The remainder of the starved cells was then transferred to rich medium and grown for DNA extraction. Figure 3B shows a Southern blot of a PstI digest of the postautogamous populations (each containing several hundred independent caryonidal clones), hybridized with probe $b$. Sample numbering is the same as in Figure 3A. In all samples except the IES - control (lane 11'), the 1.2-kb band shows that the IES was still maintained in the new macronuclear genome. The higher molecular weight fragments seen in some samples $\left(\right.$ lanes $\left.3^{\prime}, 4^{\prime}, 8^{\prime}\right)$ are PstI fragments from the plasmid monomers and dimers, attributable to the fact that a small fraction of cells had not undergone autogamy in these clones. The much smaller ratio of plasmid fragments to endogenous genomic fragment, compared with that of the preautogamous samples (Fig. 3A), is consistent with a fraction of nonautogamous cells $<1 \%$. Contaminating plasmid fragments were not always present after mass autogamies (lanes $2^{\prime}, 6^{\prime}, 7^{\prime}$ ), and were never observed when individual postautogamous caryonides from the same transformed clones were analyzed (not shown). Thus, transformation of IES + cells with varying amounts of IES - plasmid p629 does not promote excision of the IES in the new macronucleus developing after autogamy.
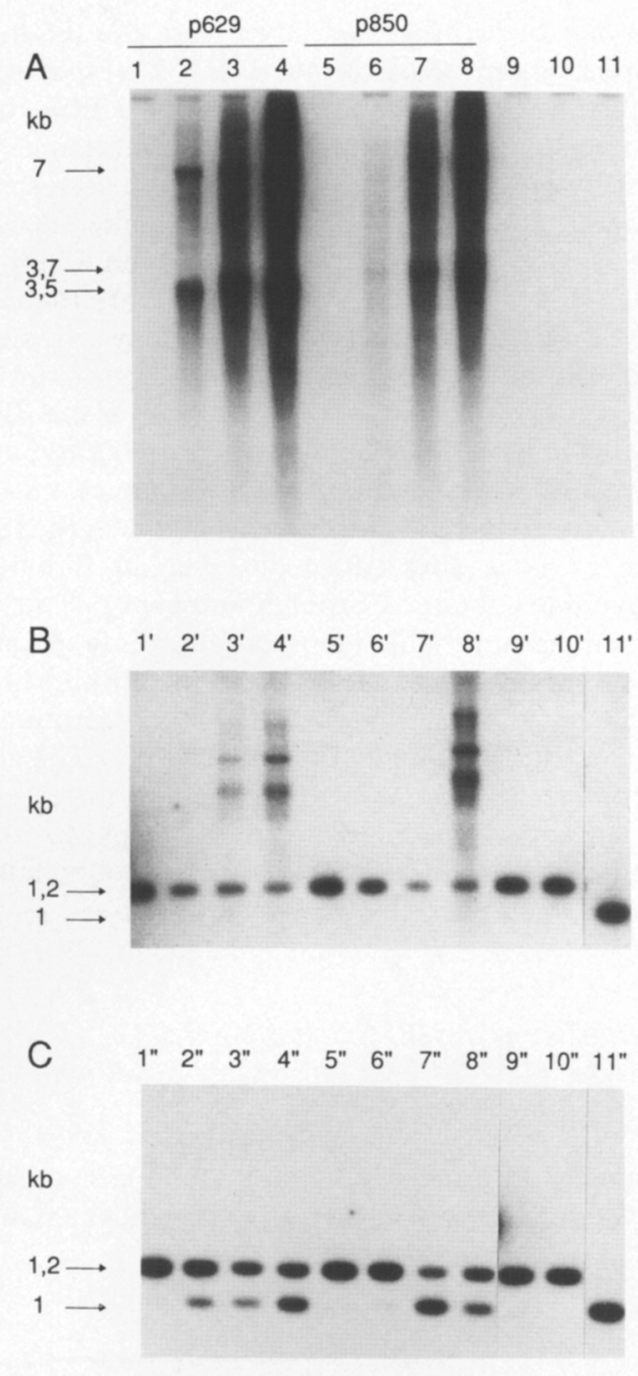

Figure 3. Effects of transformation of IES + cells with plasmids p629 and p851. (A) Southern blot of BglII-digested DNA from IES + clones transformed with p629 (lanes 1-4) or p851 (lanes 5-8), or uninjected controls (lanes 9,10). Lane 11 is an IEScontrol. The blot was hybridized with probe $b$. The thin band near the top of each lane is the high molecular weight fragment containing the endogenous IES $+G$ gene. The sizes of plasmid monomers and dimers are indicated. $(B)$ Southern blot of PstIdigested DNA from cultures obtained after autogamy of the transformed clones and uninjected controls, hybridized with probe b. The sizes of the IES + $(1.2 \mathrm{~kb})$ and IES - $(1 \mathrm{~kb}) \mathrm{G}$-gene fragments are indicated. Higher molecular weight fragments in lanes $3^{\prime}, 4^{\prime}$, and $8^{\prime}$ are contaminating plasmid fragments /see text). (C) Southern blot of PstI-digested DNA from cultures obtained after a second autogamy, hybridized with probe b.

\section{Decreased endogenous G-gene copy number after autogamy of clones transformed with $\mathrm{G}$-gene plasmids}

In Figure 3B, the amount of the $1.2-\mathrm{kb}$ genomic fragment appears to be inversely correlated to the amount of plasmid in preautogamous clones, although an approximately equal quantity of DNA was loaded onto each lane. (A quantitative analysis is presented in a later sec- 
tion; note that in lanes $4^{\prime}$ and $8^{\prime}$, the intensity of the $1.2-\mathrm{kb}$ band significantly overestimates the amount of the genomic $G$-gene fragment, because of the presence of multiple smeary bands arising from PstI digestion of the contaminating plasmid monomers and dimers.) The presence of high copy numbers of both p629 and p 851 in the old macronucleus thus results in a reduced copy number of the endogenous homologous genomic region after autogamy. This global reduction, observed in postautogamous cultures containing many different caryonidal clones, does not represent an averaging of clones totally depleted in this genomic region and clones containing a normal copy number: Cultivation and analysis of individual caryonides from the autogamous cell populations showed that each of them presents a similar copy number reduction (not shown). No copy number reduction was observed for the unlinked $C$ gene in the same samples (not shown). This is reminiscent of the effect of circular plasmids microinjected into the macronucleus of Paramecium primaurelia: Following autogamy of clones transformed with high plasmid copy numbers, specific deletions of the genomic sequences homologous to the plasmid inserts have consistently been observed in the new macronuclear genome (Meyer 1992; E. Meyer, A. Butler, and F. Caron, in prep.). In the present case, the size of the genomic region showing a decreased copy number is unknown but appears to be much larger than the plasmid inserts. Hybridization of Southern blots with different probes shows that it extends at least $6 \mathrm{~kb}$ upstream and $5 \mathrm{~kb}$ downstream of the IES; no discrete telomeric fragments or internal deletions were detected within this region (not shown).

\section{Excision can be restored in IES + cell lines}

To study possible consequences of the reduction in IES + $G$-gene copy number at nuclear reorganization, $\sim 1000$ cells from each postautogamous culture, which had been saved before DNA extraction, were again starved to induce autogamy. The results of a Southern blot analysis of the macronuclear $G$ gene after this second mass autogamy is shown in Figure 3C. The 1.2-kb PstI fragment representing the IES + form is revealed with probe $b$ in all samples except the IES - control (lane 11"). However, the $1-\mathrm{kb}$ fragment indicative of IES excision is now also observed in samples $2^{\prime}, 3^{\prime}, 4^{\prime}, 7^{\prime}$, and $8^{\prime}$, which derive from the parental cells with the smallest endogenous $G$-gene copy number (Fig. 3B). All of the 1-kb fragment in these samples could be recut by Asp 718 , showing that excision of the G-gene IES had recreated the wild-type junction (not shown). Thus, precise excision does not require the presence of the IES - $G$ gene in the old macronucleus. The total $G$-gene copy number, as estimated by the sum of both bands, was rather homogeneous. In contrast, the fraction of excised molecules appeared to be inversely correlated with the IES $+G$-gene copy number in the parental macronucleus. This suggests that developmental excision of the IES in the developing macronucleus is quantitatively inhibited, whatever the mechanism, by IES + G-gene copies in the old macronucleus.
IES + plasmid p851 can transform the IES cell line into a permanent IES + line

If this interpretation is correct, transformation of IES cells with the IES + sequence may result in retention of the IES in postautogamous macronuclei. To test this possibility, plasmids p629 and p 851 were microinjected into the vegetative macronucleus of cells of wild-type strain d4.2. Transformed cell lines were selected and cultivated as described previously. After DNA extraction, samples were digested with PvuII, which does not cut within the plasmid inserts, but cuts the pUC18 sequence $110 \mathrm{bp}$ to the left and $200 \mathrm{bp}$ to the right of the inserts, yielding a 0.9-kb fragment from the IES - plasmid p629 and a 1.1$\mathrm{kb}$ fragment from the IES + plasmid p851 (Fig. 2). Figure 4A shows a Southern blot of PvuII-digested DNA from two uninjected control clones (lanes b,c), one clone transformed with p629 (lane d), and three clones transformed with p851 (lanes e-g). Lane a is an IES + control. Plasmid copy numbers were estimated to be $\sim 2$ copies per haploid genome for p629 (clone d), and between 1 (clone e) and 10 (clone g) for p851 (see quantitative analysis). In addition to the plasmid fragments, hybridization with probe b revealed the IES - endogenous $G$ gene as a $1.6-\mathrm{kb}$ fragment in all samples, except the IES + control (lane a), where the corresponding IES + fragment is 1.8 $\mathrm{kb}$ long. A $1.8 \mathrm{~kb}$ fragment is also visible in lane $\mathrm{g}$; it is unlikely that it arises through homologous recombination between the IES + sequence of plasmid p 851 and the endogenous $G$ gene, because homologous recombination of plasmid DNA microinjected into the vegetative macronucleus of Paramecium has never been observed. This fragment probably originates from a fraction of cells in the preautogamous culture that had already undergone autogamy at the time of DNA extraction (see below).

Transformed clones were allowed to undergo a mass autogamy as in the previous experiment. A Southern blot of PstI-digested DNA from postautogamous cultures, hybridized with probe $\mathrm{b}$, is presented in Figure 4B. The IES + (lane $\left.\mathrm{a}^{\prime}\right)$ and IES - (lanes $\mathrm{b}^{\prime}$ and $\left.\mathrm{c}^{\prime}\right)$ controls showed the same pattern as their respective parents; so did the postautogamous culture from the p629-transformed clone, in which the IES was excised from all macronuclear copies (lane $\mathrm{d}^{\prime}$ ). In all postautogamous cultures derived from the p851-transformed clones, however, the IES + version was observed (lanes $\left.\mathrm{e}^{\prime}-\mathrm{g}^{\prime}\right)$. The fraction of $G$-gene copies retaining the IES in the new macronuclei appeared to correlate with the amounts of p851 plasmid in the parental macronuclei, reaching close to $100 \%$ in the $g^{\prime}$ culture. Thus, the presence in the macronucleus of an 851-bp fragment of the $G$ gene containing the IES results in the maintenance of the IES in the macronuclear genome of the following sexual generation. The IES - version of the same fragment does not appear to have the same effect: The p629-transformed clone $\mathrm{d}$ had about twice as many plasmid copies as the p851-transformed clone e; but the $\mathrm{d}^{\prime}$ postautogamous culture did not show any detectable IES + molecule, whereas e' clearly did. The g' sample also shows a decrease in the total $G$-gene copy number, similar to that 

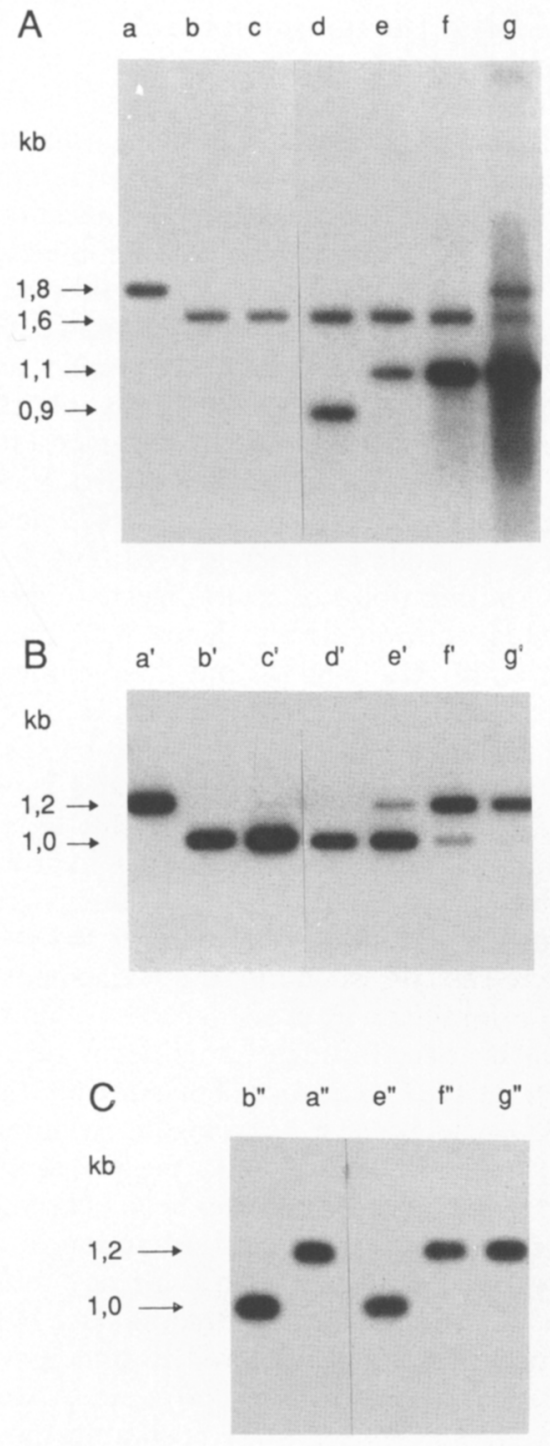

Figure 4. Effects of transformation of IES - cells with plasmids p629 and p851. (A) Southern blot of PvuII-digested DNA from an IES + control (lane $a$ ), uninjected IES - controls (lanes $b, c)$, and IES - clones transformed with p629 (lane $d$ ) or p851 (lanes $e-g$ ). The blot was hybridized with probe $b$. The sizes of the IES +11.8 $\mathrm{kb})$ and IES - $(1.6 \mathrm{~kb})$ endogenous $G$-gene fragments are indicated. The $0.9-$ and $1.1-\mathrm{kb}$ fragments arise from plasmids p 629 and $\mathrm{p} 851$, respectively. $(B)$ Southern blot of PstI-digested DNA from cultures obtained after autogamy of the transformed clones and uninjected controls, hybridized with probe $b$. The sizes of the IES + $(1.2 \mathrm{~kb})$ and IES - $(1 \mathrm{~kb}) \mathrm{G}$-gene fragments are indicated. $(C)$ Southern blot of PstI-digested DNA from cultures obtained after a second autogamy, hybridized with probe $b$.

observed after autogamy of IES + clones transformed with a high plasmid copy number (Fig. 3).

Some of the postautogamous cultures were allowed to undergo a second mass autogamy. Figure $4 \mathrm{C}$ shows a similar Southern blot analysis of the resulting cultures. The IES + (lane $\left.\mathrm{a}^{\prime \prime}\right)$ and IES - (lane $\left.\mathrm{b}^{\prime \prime}\right)$ controls presented the same patterns as their respective parents. Cul- ture $\mathrm{e}^{\prime}$, which contained a very small fraction of IES + copies, gave rise to new macronuclei containing no detectable IES + $G$ gene (lane $\left.\mathrm{e}^{\prime \prime}\right)$. Cultures $\mathrm{f}^{\prime}$ and $\mathrm{g}^{\prime}$, in which the fraction of IES + copies was very large, gave rise to postautogamous cultures with an even larger fraction of IES + copies (lanes $\left.f^{\prime \prime}, g^{\prime \prime}\right)$. The fact that $g^{\prime \prime}$ showed a very small fraction of IES - copies and $\mathrm{f}^{\prime \prime}$ did not may be related to the decrease in total G-gene copy number in $\mathrm{g}^{\prime}$ : As seen in the second autogamy of transformed IES + clones, a decreased IES + copy number results in the appearance of IES - copies after autogamy (Fig. 3B,C). Thus, the p851-induced retention of the $G$-gene IES, like that induced by the $m t F^{E}$ mutation, is maternally transmitted to sexual progeny. Other IESs appeared to be excised normally from the macronuclear genome: A PCR amplification of samples $\mathrm{f}^{\prime \prime}$ and $\mathrm{g}^{\prime \prime}$, using oligonucleotides located in the flanking sequences of four IESs from the $A$ and $B$ surface antigen genes (see Materials and methods), yielded only the expected IES sequences.

\section{Effects of modified IES + plasmids}

To test whether the apparent lack of excision induced by IES + plasmid p851 may be explained by the cut-andrepair model, modifications were introduced within the IES sequence of the plasmid (Fig. 2). In plasmid p851S, a Sall site was engineered $50 \mathrm{bp}$ from the left boundary by insertion of a synthetic oligonucleotide into a $\mathrm{BsaAl}$ site. In another construct, p851D, an internal 147-bp fragment was deleted, leaving $14 \mathrm{bp}$ of the IES sequence at the left border and $61 \mathrm{bp}$ at the right one. If transformation of the IES - macronucleus with these plasmids did inhibit excision after autogamy, a repair mechanism should result in the modified sequences being copied in the new macronucleus. On the other hand, a plasmid containing only the IES sequence, unlinked to the adjacent $G$-gene sequences, should not inhibit excision. Such a plasmid, pIES, was constructed by subcloning a restriction fragment containing all but the first $8 \mathrm{bp}$ at the left border of the IES (Fig. 2).

The results of this experiment are presented in Figure 5. Figure 5A shows a Southern blot of Pvull-digested DNA from transformed clones, hybridized with probe $b$. The 1.6-kb fragment arises from the IES - endogenous $G$ gene (lane B is an IES + clone; lane A, an uninjected IES - controll. In clones S1-S3, which were microinjected with p851S, the 1.1-kb fragment produced by digestion of the plasmid gives an indication of its copy number. Clones D1-D5 were microinjected with plasmid $\mathrm{p} 851 \mathrm{D}$, which generates a 1 -kb PvuII fragment. Clones I1-I8 were transformed with plasmid pIES, which does not contain the probe $b$ sequence. To visualize this plasmid, the blot was stripped and rehybridized with the 322-bp PvuII fragment from pUC18 (probe a), which contains the multiple cloning sequence within which all inserts were cloned. This probe reveals the $0.5-\mathrm{kb}$ PvuII fragment from pIES that contains the insert and allows a direct comparison of plasmid copy numbers in all trans- 

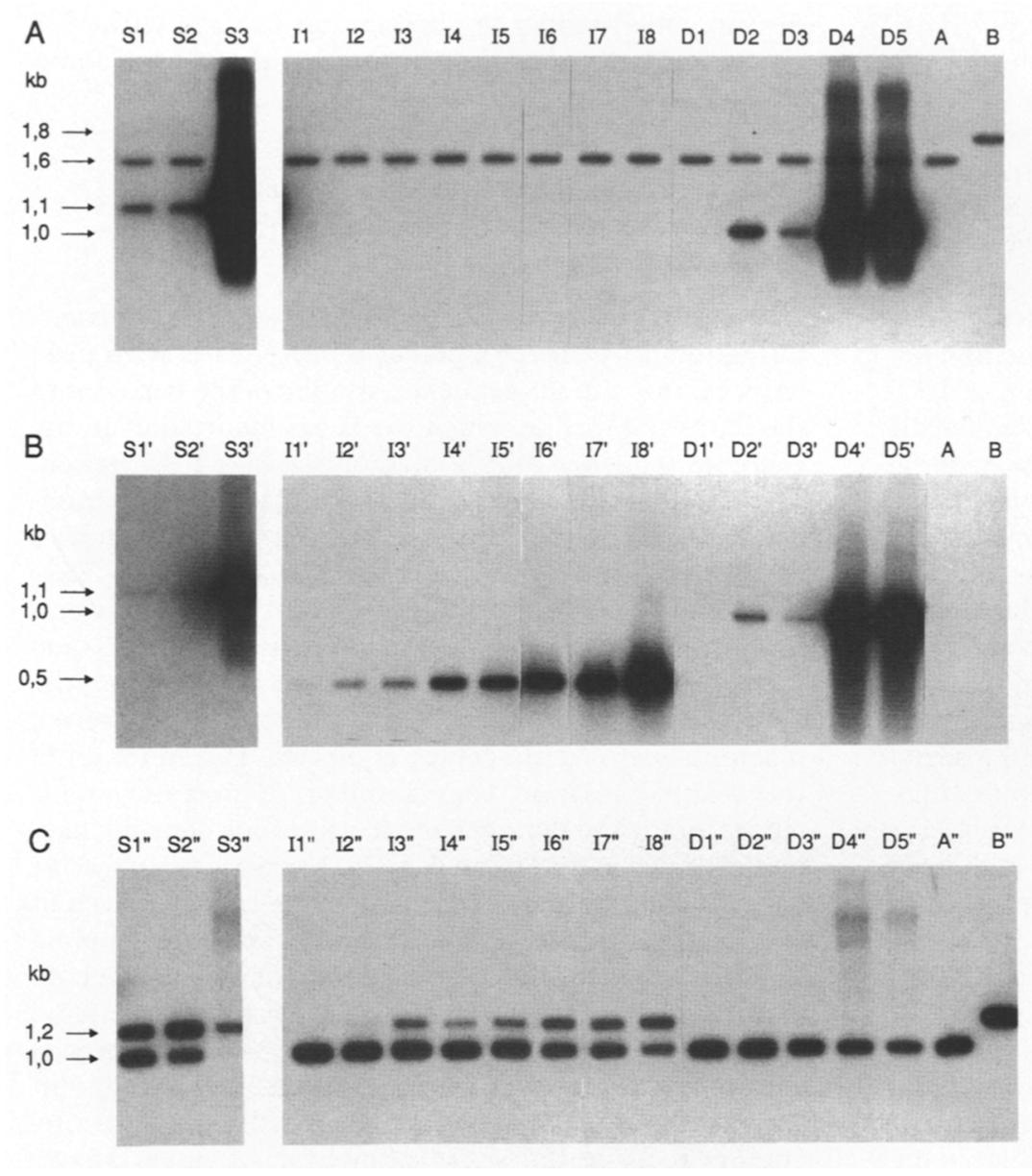

Figure 5. Effects of transformation of IES - cells with plasmids p851S, pIES, and p851D. $(A)$ Southern blot of $P$ vuII-digested DNA from an uninjected IES - control (lane A), an IES + control (lane $B$ ), and IES - clones transformed with p851S (lanes S1-S3), pIES (lanes I1-I8), and p851D (lanes $D 1-D 4)$. The blot was hybridized with probe $\mathrm{b}$. The sizes of the IES $+(1.8 \mathrm{~kb})$ and IES - $(1.6 \mathrm{~kb})$ endogenous $G$-gene fragments are indicated. The $1.1-$ and $1.0-\mathrm{kb}$ fragments arise from plasmids p851S and p851D, respectively. $(B)$ The same blot as in $A$ was stripped and rehybridized with pUC18 probe a, which allows a direct comparison of the amounts of different plasmids. The $0.5-\mathrm{kb}$ fragment arises from plasmid pIES. (C) Southern blot of PstI-digested DNA from cultures obtained after autogamy of the transformed clones and uninjected controls, hybridized with probe $\mathrm{b}$. The sizes of the IES + $(1.2 \mathrm{~kb})$ and IES $(1 \mathrm{~kb}) \mathrm{G}$-gene fragments are indicated. formed clones (Fig. 5B). Copy numbers ranged from $<1$ to $\sim 330$ copies per haploid genome (in S3).

As in previous experiments, transformed clones were allowed to undergo a mass autogamy. Figure $5 \mathrm{C}$ shows a Southern blot of PstI-digested DNA from the postautogamous cultures, hybridized with probe b. In samples $\mathrm{Sl}^{\prime}$, $\mathrm{S2}^{\prime}$, and S3', deriving from p851S-transformed clones, the $1.2-\mathrm{kb}$ fragment indicates that the new macronuclear genome contained the IES. As with p851, the fraction of IES - molecules in the new macronucleus decreases with increasing plasmid copy number in the old macronucleus. A Southern blot of Sall-digested DNA from these samples showed that the IES + form does not contain a SalI site (not shown). The IES in the new macronucleus therefore originates from the germ-line genome rather than from the plasmid of the old macronucleus.

Samples derived from pIES-transformed clones (lanes $\left.\mathrm{Il}^{\prime}-\mathrm{I}^{\prime}\right)$ also show the 1.2-kb IES + fragment. Thus, physical linkage of the IES sequence to the adjacent $G$-gene sequences is not required for the effect. Again, the fraction of IES + copies in the new macronucleus correlates with the plasmid copy number in preautogamous clones; however, for an equal copy number, plasmid pIES seems to be much less efficient than plasmid p851S (e.g., cultures S2' and $18^{\prime}$ have a similar IES + /IES - ratio, although clone 18 contained $\sim 17$ times as many plasmid copies as clone $\mathrm{S} 2$; see quantitative analysis). In contrast, the $1.2 \mathrm{~kb}$ fragment was never observed in postautogamous cultures derived from $\mathrm{p} 851 \mathrm{D}$-transformed clones, even when the plasmid copy number was very high (up to 100 copies per haploid genome). The deletion of a 147-bp fragment internal to the IES thus abolishes the effect. Finally, it should be noted that for all three plasmids, and as already described for p851 and p629, the total $G$-gene copy number appeared to be smaller in postautogamous cultures derived from clones with the highest plasmid copy numbers.

\section{Quantitative analysis of plasmid-induced reduction of G-gene copy number}

A quantitative relationship was observed in the autogamy of all transformed clones, whether IES + or IES - , between high $G$-gene plasmid copy number in the old macronucleus and reduced endogenous G-gene copy number in the new macronucleus. These variables were quantified for each clone by measuring the intensity of the corresponding bands on the Southern blots; to correct for differences in the amount of DNA loaded in each lane, the same blots were reprobed with a synthetic oligonucleotide specific for macronuclear telomeric repeats (see Materials and methods). The relative endogenous 
G-gene copy number after autogamy (the sum of IES + and IES - forms when both occur) was then plotted as a function of the relative plasmid copy number in preautogamous clones. Excluded from the analysis were samples $4 / 4^{\prime}$ and $8 / 8^{\prime}$, because a significant amount of contaminating plasmid fragments in $4^{\prime}$ and $8^{\prime}$ precluded an accurate determination of the G-gene copy number in the new macronucleus (Fig. 3B). The plot is shown in Figure 6. Relative copy numbers on both axes are expressed as number of copies per haploid genome, the reference value of one copy per haploid genome $(\sim 1000$ copies per macronucleus) being arbitrarily fixed as the average relative $G$-gene copy number in four postautogamous cultures derived from uninjected controls, which showed a $9 \%$ variation between the two extreme values. In spite of this variability, which may be ascribed to measurement errors or natural variation of the $G$-gene copy number or amount of telomeric repeats, a clear correlation appears: the endogenous $G$-gene copy number after autogamy decreases regularly with increasing plasmid copy numbers in preautogamous clones, in a seemingly logarithmic way. The most outlying point (indicated by an arrow) corresponds to sample $\mathrm{g} / \mathrm{g}^{\prime}$ (Fig. 4); the plasmid copy number in clone $\mathrm{g}$ is probably underestimated because a fraction of the cells in this preautogamous culture had already undergone autogamy at the time of DNA extraction. It can be noticed that the postautogamous progeny of clones transformed with a small plasmid copy number (less than six to seven copies) appear to have a $G$-gene copy number larger than one, that is, larger than that of the postautogamous progeny of uninjected controls; the reason for this slight bias is unclear. Overall, the effects of different plasmids are not significantly different. A logarithmic function fitted among all points indicates that a $50 \%$ reduction in
G-gene copy number is obtained on average with $\sim 70$ plasmid copies per haploid genome in the old macronucleus.

Quantitative analysis of the induction of IES retention by the IES sequence in the old macronucleus

The experiments presented here have shown that transformation of the macronucleus of IES - cells with plasmids bearing the IES sequence simulates the behavior of the IES + cell line, in which the IES is maintained in the genomic sequence during macronuclear differentiation. The effect is strongly dependent on plasmid copy number. To quantify the difference noted in the efficiency of different plasmids, the proportion of IES + and IES molecules was determined for all postautogamous cultures by measuring the relative intensities of the 1.0- and $1.2-\mathrm{kb}$ PstI fragments revealed with probe $\mathrm{b}$ on the Southern blots. In Figure 7, the percentage of excised macronuclear $G$-gene copies is plotted as a function of the relative plasmid copy number in preautogamous clones, using the same reference value (one copy per haploid genome) as in Figure 6. p851D serves as a negative control: This plasmid had no effect on excision, even at very high copy numbers /up to 100 copies per haploid genome, i.e., $\sim 100,000$ copies per macronucleus). In contrast, about five copies of the p851 plasmid per haploid genome resulted in only $11 \%$ of IES - G-gene copies in the new macronucleus. Plasmid p851S, which only differs from $\mathrm{p} 851$ by the presence of an additional Sall site, appears to have the same efficiency. As noted above, plasmid pIES was much less efficient: With $\sim 60$ copies per haploid genome, $44 \%$ of the $G$-gene copies in the new macronucleus were still IES -.
Figure 6. Quantitative analysis of plasmid-induced reduction of $G$-gene copy number. The relative $G$-gene copy number in the new macronucleus is plotted as a function of the plasmid copy number in preautogamous clones, on a logarithmic scale. Both variables are expressed as number of copies per haploid genome, with the 1.0 reference value being the average relative $G$-gene copy number in postautogamous cultures derived from uninjected controls (see text and Materials and methods). The arrow points to the $\mathrm{g} / \mathrm{g}$ ' sample; the plasmid copy number is probably underestimated in $g$ (see text). Symbols for plasmids and recipient cells: ( $\mathbf{A}$ ) p629/IES + ; p851/IES + ; (O) p851/IES - ; (O) p850S/IES - ; $(\triangle)$ pIES/IES - ; (口) p850D/IES - .

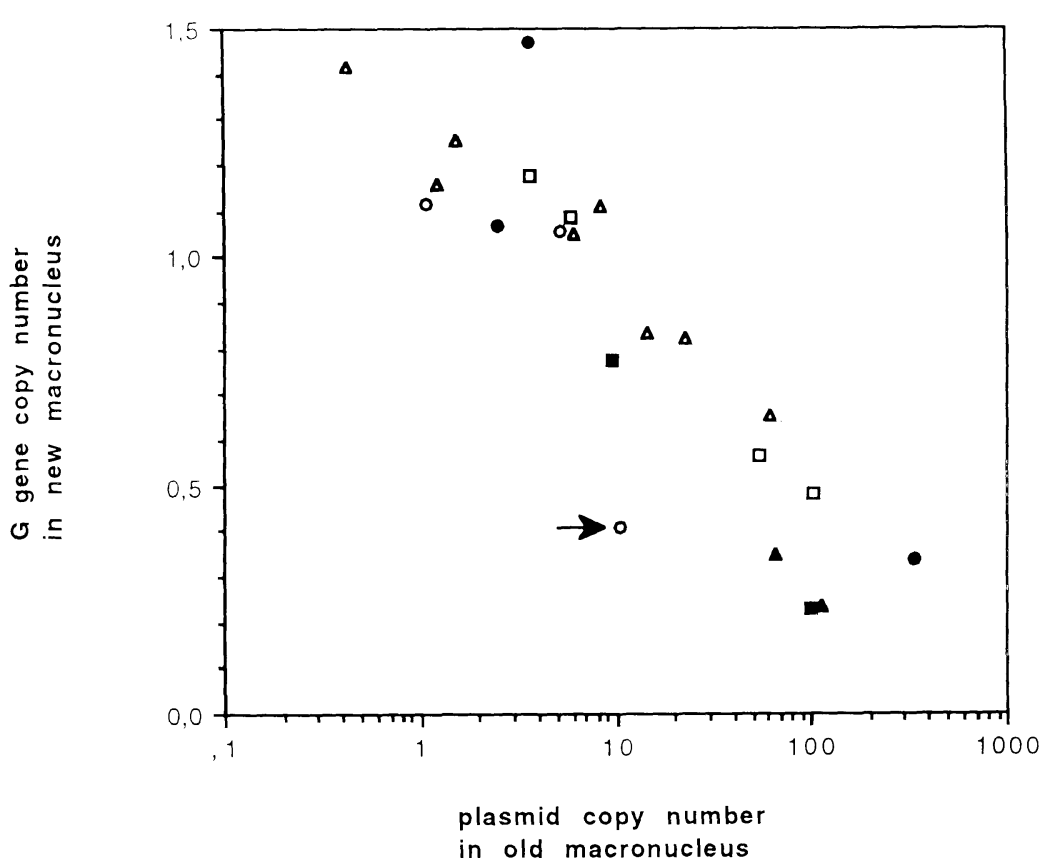




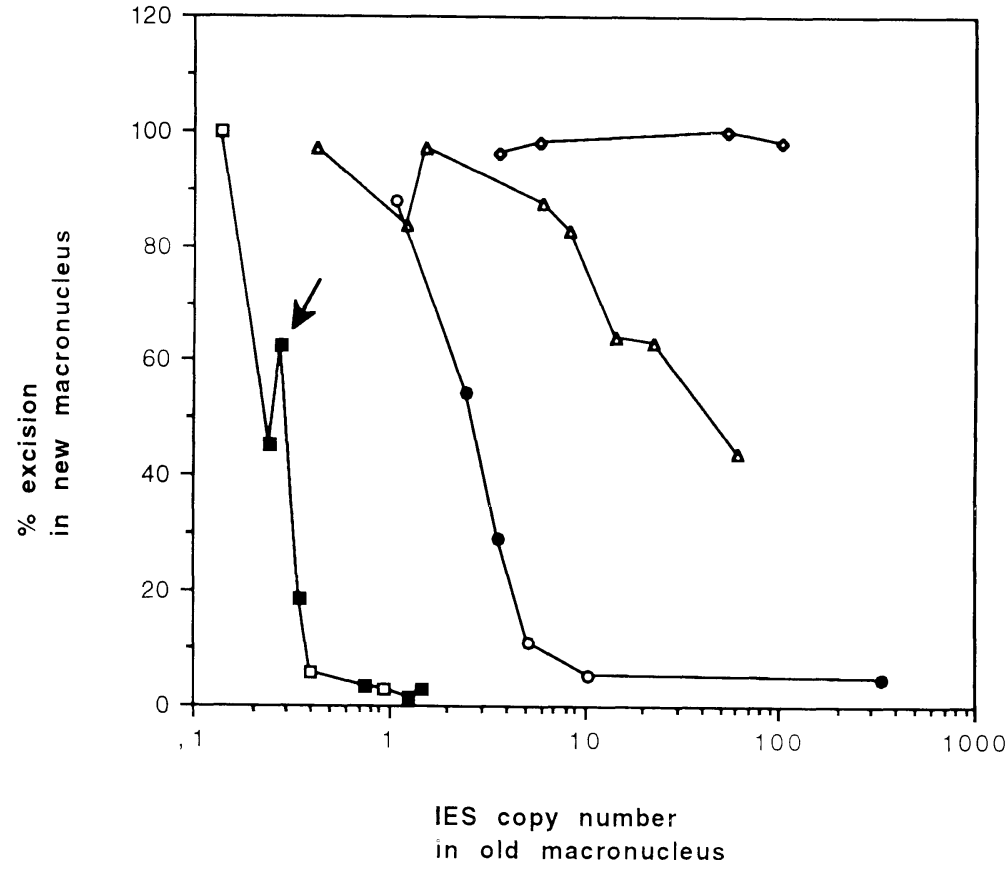

Figure 7. Quantitative analysis of the effect of the IES in the old macronucleus on the retention of the IES in the new macronuclear genome. The fraction of IES - $G$-gene copies in the postautogamous samples is plotted as a function of the relative copy number of the IES sequence in preautogamous samples, i.e., IES - clones transformed with IES + plasmids p851D $(\diamond)$, pIES $(\triangle), \mathrm{p} 851(O)$, and p851S $(\bullet)$ or uninjected clones with various endogenous IES + G-gene copy numbers: samples $1^{\prime}, 2^{\prime}, 3^{\prime}, 5^{\prime}, 6^{\prime}$, and $7^{\prime}$ of Fig. 3B

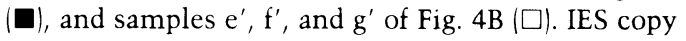
numbers are expressed as numbers of copies per haploid genome (see text). The arrow points to sample $3 / 3^{\prime}$; the IES + G-gene copy number in $3^{\prime}$ is probably overestimated (see text). Data from the experiments involving plasmids $\mathrm{p} 851$ and $\mathrm{p} 851 \mathrm{~S}$, which only differ by a Sall site and appear to have similar efficiencies, are shown in a single graph.
The complete absence of IES - G-gene in the uninjected IES + cell line indicates that the effect of the endogenous IES + genomic sequence in the old macronucleus must be stronger than that of IES + plasmid p851, because one copy per haploid genome should be sufficient to maintain the IES on $100 \%$ of copies in the new macronucleus. The effect of subgenomic copy numbers of the chromosomal IES sequence can be studied quantitatively, using the cultures with various proportions of IES + and IES - copies (lanes $\mathrm{e}^{\prime}-\mathrm{g}^{\prime}$ in Fig. 4B), which were obtained by autogamy of p851-transformed IES clones, and those with a reduced IES + copy number but no IES - copies (Fig. 3B samples), which were obtained by autogamy of transformed IES + clones. The copy number of the IES + $G$ gene in these cultures was determined by measuring the intensity of the $1.2-\mathrm{kb}$ Pst I fragment revealed with probe $b$ and normalizing with the telomeric signal. After these cultures had undergone an additional autogamy, the percentage of excision in the new macronucleus (Fig. 4C, lanes $\mathrm{e}^{\prime \prime}, \mathrm{g}^{\prime \prime}$; Fig. 3C samples) was measured as the relative intensities of the 1.0and 1.2-kb PstI fragments and plotted as a function of the IES + G-gene copy number in the old macronucleus (expressed as a number of copies per haploid genome, using the same reference value). Thus, in Figure 7, the effect of various copy numbers of the chromosomal IES can be compared directly to the effect of various copy numbers of the IES sequence carried by plasmids p 851 and pIES. Samples $4^{\prime} / 4^{\prime \prime}$ and $8^{\prime} / 8^{\prime \prime}$ were again excluded from the analysis, for the reason mentioned above. Here, again, the proportion of IES - copies in the new macronucleus decreases with increasing IES + copy numbers in the old macronucleus. The fact that the genomic plot is not monotonously decreasing is probably attributable to a slight overestimation of the IES $+G$-gene copy number in the preautogamous sample 3' (indicated by an arrow in Fig.
7), which contained a small amount of contaminating plasmid fragments (Fig. 3B). As expected, the decrease is more rapid than with any of the plasmids. With 0.4 copy per haploid genome of the IES + $G$ gene in the old macronucleus, only $\sim 6 \%$ of $G$-gene copies are excised in the new macronucleus.

\section{Discussion}

Epigenetic regulation of developmental processing of the G-gene IES

IES + cell lines were initially obtained as $m t F^{+} / m t F^{+}$ homozygotes by the autogamy of an $m t F^{E} / m t F^{+}$heterozygote in the mutant cytoplasmic lineage and were therefore inferred to have a completely wild-type germline genome (E. Meyer and A.-M. Keller, in prep.). Conjugation with an IES - wild-type cell line confirmed that the alternative processing leading to the IES + or IES macronuclear versions of the $G$ gene is not genetically determined in zygotic nuclei. It was also shown that excision of the $G$-gene IES can be experimentally induced in the IES + line by decreasing the macronuclear IES + $G$-gene copy number (which follows from the massive injection of plasmids p629 or p851). Because neither microinjection of plasmids into the macronucleus nor autogamy of a homozygous cell can modify the germ-line genome, this provides an independent demonstration that the IES + cell line is genetically competent for excision of this IES. Conversely, we have shown that transformation of the macronucleus of wild-type IES - cells with IES + plasmid p851 results in the retention of the IES in the new macronucleus differentiating after autogamy. This effect depends on the presence of the IES sequence in the plasmid insert, because it is not shared by plasmid p629, which contains the IES - version of the 
same restriction fragment, or by plasmid p851D, in which about two-thirds of the IES sequence was deleted. Although the germ-line genome was not modified in this experiment, the p851-induced IES + character was itself transmitted to sexual progeny, like that induced by the $m t F^{E}$ mutation. This demonstrates that nothing other than the presence of a fragment of the IES $+G$ gene in the old macronucleus is required to turn an IES - wildtype strain into a stable IES + cell line. Thus, during macronuclear differentiation in wild-type cells, excision or retention of the $G$-gene IES only depends on the structure and copy number of the $G$ gene in the old macronucleus.

\section{Developmental excision is inhibited by the presence} of the IES in the old macronucleus

The cut-and-repair model, proposed to account for the maternal inheritance of the IES + and IES - characters, postulates that a double-strand gap is created in the $G$ gene by constitutive excision of the IES during macronuclear development in both IES + and IES - cell lines and then repaired by the copying of a homologous template from the old macronucleus. The failure of IES plasmid p629 to activate excision in the IES + cell line, as well as the reappearance of precise excision after autogamy of clones with a reduced IES + G-gene copy number but devoid of IES - $G$ gene, indicate that such a mechanism is not involved in the production of the correct IES - junction. Can the model still apply to the production of the IES + macronuclear version? If excision is initiated by a cut at each end of the IES, as proposed in hypotrichous ciliates for both IESs and transposon-like elements (Klobutcher et al. 1993; Jaraczewski and Jahn 1993; Williams et al. 1993), and shown for a programmed deletion event in the more closely related Tetrahymena (Saveliev and Cox 1995), a prediction of the model is that retention of the $G$-gene IES in the new macronucleus will critically depend on the physical linkage of IES and flanking sequences in the old macronucleus. This is not borne out by the transformation of IES - cells with plasmid pIES, which results in IES retention. The effects of modified IESs also run contrary to predictions of the model. The IES + macronuclear $G$ gene recovered after autogamy of p851S-transformed IES - cells contains the germ-line IES sequence, not the modified IES sequence present on the plasmid. Furthermore, an internal modification of the IES sequence in plasmid p851D abolishes the effect, which would not be expected.

Thus, the maternal inheritance of the IES + and IES characters appears to be attributable to an inhibition of excision of the $G$-gene IES in the developing macronucleus of the IES + cell line, caused by the presence of the IES in the old macronucleus; no effect of the IES - $G$ gene in the old macronucleus was evidenced. The results obtained with transformed cells are consistent with those obtained from uninjected cells with various endogenous IES + and IES - G-gene copy numbers. The quantitative analysis shows that the percentage of excision in the new macronucleus is inversely correlated with the number of copies of the IES + G gene in the old macronucleus, as observed after injection of IES + plasmids in IES - cells (Fig. 7). However, excision appears to be more sensitive to the genomic IES + sequence than to the IES + plasmids: $90 \%$ inhibition is obtained with only 0.3-0.4 IES + genomic copies per haploid genome in the old macronucleus or $\sim 6$ copies of plasmid p851, whereas plasmid pIES only results in $56 \%$ inhibition with 60 copies.

\section{Possible mechanisms of excision inhibition} by the maternal IES

During meiosis and fertilization, the old macronucleus breaks up into $\sim 30$ fragments in which DNA synthesis is progressively inhibited; these fragments remain transcriptionally active for the whole period of development of new macronuclei (Berger 1973). The mechanism through which the presence of the IES $+G$ gene in the old macronucleus inhibits the developmental excision of the $G$-gene IES in the developing macronuclei has to operate through the cytoplasm because fusion of the fragments of the old macronucleus with the developing macronuclei is not observed under normal conditions. Two different types of mechanisms can be proposed. First, the IES $+G$ gene in the old macronucleus could compete with the germ-line sequence for a protein factor necessary for IES excision, by titrating it out of the cytoplasm. Alternatively, a trans-acting factor could be actively produced from the IES + G gene in the old macronucleus and be exported to the developing macronucleus to inhibit excision. In both cases, the putative trans-acting factor would have to show some specificity for the $G$-gene IES. The vast majority of germ-line IESs are correctly excised in the IES + cell lines obtained by p851 transformation, as shown by their wild-type phenotype: Given the very large number of IESs in the genome, an excision defect affecting a significant fraction of them would almost certainly be lethal. A PCR analysis further confirmed the correct excision of four other IESs, located in the $A$ and $B$ surface antigen genes.

The first type of mechanism would require that the putative excision factor, after its synthesis in the cytoplasm, be able to circulate freely in and out of the fragments of the old macronucleus before it reaches the developing macronucleus, to explain its total lack of action in IES + cells. Furthermore, the complete titration of the factor by a small amount of IES $+G$ gene in the old macronucleus $(90 \%$ inhibition of excision with only 0.4 copy per haploid genome, i.e., $\sim 400$ copies per macronucleus) would imply a high degree of specificity for the $G$-gene IES because there is no evidence for any other unexcised IES. However, highly specific protein factors are certainly not a general feature of IES excision: IESs appear to be noncoding, so that such factors would have to be encoded elsewhere in the genome. Moreover, the absence of any effect of the p851D plasmid on excision indicates that the binding site for the putative factor would have to be located within the internal 147-bp IES segment that is deleted in this plasmid. This is difficult 
to reconcile with the quantitatively different efficiencies of plasmid pIES, plasmid p851, and the genomic IES + sequence, which all include the 147-bp segment.

In the second type of mechanism, an excision-inhibiting factor would be produced from the IES $+G$ gene in the old macronucleus. Because the G-gene IES is apparently not coding (it is $80 \% \mathrm{~A}+\mathrm{T}$ and does not contain any open reading frame) and because inhibition is observed after transformation with pIES, which only contains $214 \mathrm{bp}$ of the IES, the inhibiting factor is not likely to be a protein. We propose that the IES sequence itself, or an RNA copy of it, is exported to the developing macronucleus, where it acts by pairing with the homologous germ-line sequence. Such a sequence-specific mechanism would readily explain why the excision of other IESs in the $A$ and $B$ genes is not affected by the $G$-gene IES in the old macronucleus. In this model, the stepwise increase in the efficiency of excision inhibition by the IES sequence, as one goes from pIES to $\mathrm{p} 851$ and to the IES + genomic sequence, might be explained by the different lengths of flanking-sequence homology to the germ-line sequence, which could lead to differences in pairing efficiency. The absence of excision inhibition by plasmids p629 and p851D would indicate that the pairing of the 147-bp segment (or simply pairing over a minimum length of the IES sequence) is required. However, all plasmids induce a quantitatively similar reduction of the $G$-gene copy number after autogamy. The fact that some of them, such as p629 and pIES, do not bear any common sequence, suggests that the copy number reduction effect also involves pairing rather than the titration of multiple sequence-specific proteins factors, as has been proposed for yet other effects of injected plasmids: the general and sequence-specific induction of deletions in P. primaurelia (Meyer 1992; E. Meyer, A. Butler, and F. Caron, in prep.), and the rescue of mutant telomere addition patterns in P. tetraurelia (Kim et al. 1994; You et al. 1994).

Although the data do not rule out the titration of a specific excision factor, the above arguments lead us to favor a pairing mechanism. Because it appears that retention of the IES is not attributable to repair synthesis, pairing could affect an earlier step of the excision process, which could be the recognition of the sequence to be excised, the formation of a functional excision complex, or an initial endonucleolytic cleavage. It would be of great interest to know whether a similar epigenetic regulation of excision is observed for other IESs in the genome. Experiments are now in progress to test this point and to determine the full extent of the sequence specificity of excision inhibition. Whatever the mechanism may be, its study is likely to bring new insight into the general process of IES excision.

\section{Biological significance of epigenetic self-regulation of excision}

The observation that IES excision can be epigenetically regulated in wild-type cells, like alternative telomere addition regions, highlights the great developmental plas- ticity of the Paramecium macronuclear genome. Both types of genomic rearrangements may therefore help to explain the old observation that individual caryonides from entirely homozygous strains can display a number of stable alternative phenotypic characters that are irreversibly determined during macronuclear differentiation from a totipotent germ-line genome, with or without maternal inheritance (Sonneborn 1977; Sonneborn and Schneller 1979; Epstein and Forney 1984; Nyberg 1986).

The quantitative analysis presented in this study shows that any clone containing between 0.1 and 1 copy per haploid genome of the IES + G-gene version in its macronuclear genome will give rise to postautogamous progeny with a larger fraction of IES + copies. Only two alternative macronuclear states are therefore expected to be stably maintained through successive autogamies $(0 \%$ and $100 \%$ IES + copies $)$, explaining the stability of IES - and IES + cell lines. It should be pointed out that the dynamics of the epigenetic regulation system described here could fully account for puzzling features of the mating-type determination system in P. tetraurelia, the molecular mechanism of which is unknown. In addition to the maternal inheritance of two alternative differentiated types (Sonneborn 1977), these include the occasional and transient occurrence of mixed macronuclei in selfer clones (Nanney 1957) and the genetic restriction to one of the developmental alternatives by the pleiotropic $m t F^{E}$ mutation (Brygoo and Keller 1981b; E. Meyer and A.-M. Keller, in prep.).

\section{Materials and methods}

Cell lines and cultivation

$P$. tetraurelia wild-type strain $\mathrm{d} 4.2$ is a well-characterized derivative of stock 51 carrying the $29 A$ allele of the $A$ surface antigen gene, and gene $k$ (Sonneborn 1974). Cells were grown in a wheat grass powder (Pines International Co., USA) infusion medium bacterized the day before use with Klebsiella pneumoniae and supplemented with $0.8 \mathrm{mg} /$ liter of $\beta$-sitosterol (Merck, Darmstadt FRG), at $18^{\circ} \mathrm{C}$ or $27^{\circ} \mathrm{C}$. Basic methods of cell culture have been described (Sonneborn 1970).

\section{Autogamy and conjugation}

Autogamy was induced by starving the cells after they had reached the appropriate clonal age ( 30 vegetative divisions) and assessed by staining with a $15: 1$ ( $\mathrm{vol} / \mathrm{vol}) \mathrm{mix}$ of carmine red $(0.5 \%$ in $45 \%$ acetic acid) and fast green (1\% in ethanol). For caryonidal analyses, cells were isolated from depressions showing $100 \%$ autogamous cells. After the first cellular division, the two caryonides were isolated and cultivated separately. For mass autogamies, a whole depression $(\sim 1000$ autogamous cells $)$ was transferred to bacterized medium and grown collectively. Conjugation was induced by starving two clones with complementary mating types. Pairs firmly engaged in conjugation were transferred to individual depressions. The two exconjugants from each pair were isolated after their separation; After the first division, the two caryonides from each exconjugant were again isolated and grown separately. Their parental origins were determined by mating type testing of derived $\mathrm{F}_{2}$ postautogamous cells, using standard $\mathrm{d} 4.2$ tester strains /mating type is maternally inherited). 


\section{Dot-blot analyses}

For each sample, $\sim 500$ cells were pipetted from depression slide cultures and transferred to $400 \mu \mathrm{l}$ of $0.4 \mathrm{~N} \mathrm{NaOH}, 50 \mathrm{~mm}$ EDTA. The lysates were incubated for $30 \mathrm{~min}$ at $68^{\circ} \mathrm{C}$ and loaded on a Hybond $\mathrm{N}^{+}$membrane (Amersham, $\mathrm{UK}$ ) using a dot-blot apparatus. The membrane was kept wet with $0.4 \mathrm{~N} \mathrm{NaOH}$ for 15 min, washed in $2 \times$ SSC (SSC is $0.15 \mathrm{M} \mathrm{NaCl}, 0.015 \mathrm{M}$ sodium citrate), and treated further as a Southern blot.

\section{Microinjection of plasmids}

Young cells (less than eight fissions after autogamy) were injected in Volvic mineral water (Volvic, France) containing $0.2 \%$ BSA, under an oil film (Nujol) while being visualized with a phase-contrast inverted microscope (Axiovert 35M, Zeiss). CsCl-purified plasmid DNA was linearized within the pUC18 vector sequence with ScaI (p629, p851, p851D) or XmnI (pIES, p851S), extracted with phenol, filtered on a $0.22-\mu \mathrm{m}$ MillexGV4 filter (Millipore), and precipitated with ethanol. Approximately $5 \mathrm{pl}$ of a $5 \mathrm{mg} / \mathrm{ml}$ solution in water were delivered into the macronucleus.

\section{Genomic DNA extraction}

Cultures of exponentially growing cells $(400 \mathrm{ml})$ at 1000 cells/ $\mathrm{ml}$ were centrifuged. After being washed in Volvic mineral water, the pellet was resuspended in one volume of mineral water and added quickly to four volumes of lysis solution $10.44 \mathrm{M}$ EDTA at pH 9.0, 1\% SDS, $0.5 \% \mathrm{~N}$-laurylsarcosine (Sigma), and $1 \mathrm{mg} / \mathrm{ml}$ of proteinase $\mathrm{K}($ Merck $)$ at $55^{\circ} \mathrm{C}$. The lysate was incubated at $55^{\circ} \mathrm{C}$ for at least $5 \mathrm{hr}$, gently extracted once with phenol, and dialyzed twice against TE $(10 \mathrm{~mm}$ Tris- $\mathrm{HCl}, 1 \mathrm{~mm}$ EDTA at $\mathrm{pH} 8.0$ ) containing $20 \%$ ethanol, and once against TE.

\section{Southern blot analyses}

DNA restriction and electrophoresis were carried out according to standard procedures (Sambrook et al. 1989). DNA was transferred from agarose gels to Hybond $\mathrm{N}^{+}$membranes (Amersham, $\mathrm{UK}$ ) in $0.4 \mathrm{~N} \mathrm{NaOH}$ after depurination in $0.25 \mathrm{~N} \mathrm{HCl}$. Prehybridization and hybridization were carried out in $7 \%$ SDS, $0.5 \mathrm{M}$ sodium phosphate, $1 \% \mathrm{BSA}$, and $1 \mathrm{~mm}$ EDTA $(\mathrm{pH} 7.2)$ at $61^{\circ} \mathrm{C}$ (Church and Gilbert 1984). Probes were labeled using a random priming kit (Boehringer Mannheim, Germany) to a sp. act. of $3.10^{9} \mathrm{cpm} / \mu \mathrm{g}$. Membranes were then washed for $30 \mathrm{~min}$ in $0.2 \times$ SSC and $0.5 \%$ SDS at $60^{\circ} \mathrm{C}$ prior to autoradiography or PhosphorImager quantification.

\section{PCR amplification}

Oligonucleotides were designed in the flanking sequences of IESs according to published sequences for the $51 \mathrm{~A}$ IESs 2591 (ACACCAAGCGAAACATGCACAGTCG, TTTTA-TGGCATTAAGCTTGTGTCAT) and 4404 (TAAATGTTCAGCTTACAACGCAGCT, TAGAAGTTGAAATACATTTATTTTG (Steele et al. 1994), and the 51B IESs 1417 (CTTGTGTTAAAAACTCTTCTGGAGC, CTGTACAAGATGATAAA-AAGGCAAC) and 5464 (TGGATGCCAGCTGTAGGAACTAACT, AAGCTGATTCAGAGGTTAATGTTGC) (Scott et al. 1994b). All sequences are $5^{\prime} \rightarrow 3^{\prime}$. Amplifications were carried out in capped $0.5-\mathrm{ml}$ Sigma polypropylene tubes, using a PerkinElmer Cetus thermocycler. Reactions $(25 \mu \mathrm{l})$ contained $100 \mathrm{ng}$ of genomic DNA, $1 \times$ PCR buffer supplied by the manufacturer (Epicentre), $200 \mu \mathrm{M}$ of each $\mathrm{dNTP}$, and $4 \mu \mathrm{M}$ of each oligonucleotide. The amplification was run for 23 cycles $\left(92^{\circ} \mathrm{C}, 1 \mathrm{~min}\right.$; $63^{\circ} \mathrm{C}, 1 \mathrm{~min} 15 \mathrm{sec}$, except for the $51 \mathrm{~A} 4404$ pair, where the annealing temperature was $55^{\circ} \mathrm{Cl}$.

Quantification of endogenous G gene and plasmid copy numbers.

The endogenous $G$-gene copy number was determined by measuring the intensity of the PstI fragments revealed with probe $b$ using a PhosphorImager (Molecular Dynamics). To correct for differences in the amount of DNA loaded in each lane, the figures obtained were normalized by reprobing the same blots with a 30-bp degenerate oligonucleotide specific for macronuclear telomeric repeats, $\left.\left[5^{\prime}-(\mathrm{C} / \mathrm{A}) \mathrm{AACCC}-3^{\prime}\right)\right|_{5}$; the telomeric signal, counted on the whole length of the lane, can be expected to a more reliable estimate of the total amount of macronuclear DNA on the blots than the signal from any genomic probe, because it does not depend on copy number variation of a particular macronuclear chromosome. Furthermore, neither macronuclear telomere length nor total amount of telomeric repeats vary significantly with clonal age (Gilley and Blackburn 1994). The linearity of the telomeric probe response was checked by quantifying the signal obtained with various amounts of the same genomic sample. Plasmid copy numbers were determined for all preautogamous transformed lines by hybridizing $P_{V u I I}$ digests with the pUC18 probe a, as shown in Figure $5 \mathrm{~B}$. The correspondence between probe $\mathrm{a}$ and $\mathrm{b}$ signals is given by transformed clones such as d and e (Fig. 4A), in which the same PvuII plasmid fragment contains the sequences of both probes. The ratio can then be used to convert the probe a signal from each transformed clone into the equivalent probe $\mathrm{b}$ signal, and furthermore, after normalization with the telomeric signal, into relative plasmid copy number. This method could lead to an underestimation of high plasmid copy numbers if the presence of plasmid telomeres significantly increases the telomeric signal from transformed cells; however, this would only underestimate the efficiency difference noted between IES + plasmids and IES + endogenous $G$ gene in excision inhibition.

\section{Acknowledgments}

We thank L. Amar, M. Bétermier, F. Caron, K. Dubrana, A.-M. Keller, and A. Le Mouël for critical readings of the manuscript and helpful discussions. This work was supported by grant 30 from the Groupement de Recherches et d'Etudes sur les Génomes, BP25, 91193 Gif-sur-Yvette CEDEX, France. S. Duharcourt is recipient of a doctoral fellowship from the Ministère de l'Enseignement Supérieur et de la Recherche.

The publication costs of this article were defrayed in part by payment of page charges. This article must therefore be hereby marked "advertisement" in accordance with 18 USC section 1734 solely to indicate this fact.

\section{References}

Berger, J.D. 1973. Nuclear differentiation and nucleic acid synthesis in well-fed exconjugants of Paramecium aurelia. Chromosoma 42: 247-268.

Brygoo, Y. and A.-M. Keller. 1981a. A mutation with pleiotropic effects on macronuclearly differentiated functions in Paramecium tetraurelia. Dev. Genet. 2: 23-34.

- 1981b. Genetic analysis of mating type differentiation in Paramecium tetraurelia. III. A mutation restricted to mating type $E$ and affecting the determination of mating type. Dev. Genet. 2: 13-22.

Church, G.M. and W. Gilbert. 1984. Genomic sequencing. Proc. 
Natl. Acad. Sci. 81: 1991-1995.

Doak, T.G., F.P. Doerder, C.L. Jahn, and G. Herrick. 1994. A proposed superfamily of transposase genes: Transposon-like elements in ciliated protozoa and a common "D35E" motif. Proc. Natl. Acad. Sci. 91: 942-946.

Engels, W.R., D.M. Johnson-Schlitz, W.B. Eggleston, and J. Sved. 1990. High-frequency P element loss in Drosophila is homolog dependent. Cell 62: 515-525.

Epstein, L.M. and J.D. Forney. 1984. Mendelian and non-Mendelian mutations affecting surface antigen expression in Paramecium tetraurelia. Mol. Cell. Biol. 4: 1583-1590.

Gilley, D. and E.H. Blackburn. 1994. Lack of telomere shortening during senescence in Paramecium. Proc. Natl. Acad. Sci. 91: 1955-1958.

Jaraczewski, J.W. and C.L. Jahn. 1993. Elimination of Tec elements involves a novel excision process. Genes \& Dev. 7: 95-105.

Keller, A-M., A. Le Mouël, F. Caron, M. Katinka, and E. Meyer. 1992. The differential expression of the G surface antigen alleles in Paramecium primaurelia heterozygous cells correlates to macronuclear DNA rearrangement. Dev. Biol. 13: $306-317$.

Kim, C.S., J.R. Preer, Ir., and B. Polisky. 1994. Identification of DNA segments capable of rescuing a non-Mendelian mutant in Paramecium. Genetics 136: 1325-1328.

Klobutcher, L.A. and G. Herrick. 1995. Consensus inverted terminal repeat sequence of Paramecium IESs: Resemblance to termini of Tcl-related and Euplotes transposons. Nucleic Acids Res. 23: 2006-2013.

Klobutcher, L.A., L.R. Turner, and J. LaPlante. 1993. Circular forms of developmentally excised DNA in Euplotes crassus have a heteroduplex junction. Genes \& Dev. 7: 84-94.

Meyer, E. 1992. Induction of specific macronuclear developmental mutations by microinjections of a cloned telomeric gene in Paramecium primaurelia. Genes \& Dev. 6: 211-222.

Nanney, D.L. 1957. Mating type inheritance at conjugation in variety 4 of Paramecium aurelia. I. Protozool. 4: 89-95.

Nyberg, D. 1986. Cytoplasmic inheritance of temperature sensitivity in a wild stock of Paramecium primaurelia. I. Protozool. 33: 38-41.

Plasterk, R.H.A. 1991. The origin of footprints of the Tcl transposon of Caenorhabditis elegans. EMBO I. 10: 1919-1925.

Prescott, D.M. 1994. The DNA of ciliated protozoa. Microbiol. Rev. 58: 233-267.

Sambrook, J., E.F. Fritch, and T. Maniatis. 1989. Molecular cloning: A laboratory manual, 2nd ed. Cold Spring Laboratory Press, Cold Spring Harbor, New York.

Saveliev, S.V. and M.M. Cox. 1995. Transient DNA breaks associated with programmed genomic deletion events in conjugating cells of Tetrahymena thermophila. Genes \& Dev. 9: 248-255.

Scott, J.M., K. Mikami, C.L. Leeck, and J.D. Forney. 1994a. NonMendelian inheritance of macronuclear mutations is genespecific in Paramecium tetraurelia. Mol. Cell. Biol. 14: 2479-2484.

Scott, J., C. Leeck, and J. Forney. 1994b. Analysis of the micronuclear B type surface protein gene in Paramecium tetraurelia. Nucleic Acids Res. 22: 5079-5084.

Sonneborn, T.M. 1970. Methods in Paramecium research. Methods Cell Physiol. 4: 241-339.

. 1974. Paramecium aurelia. In Handbook of genetics: Plants, plant viruses and protists (ed. R.C. King), vol. 2, pp. 469-594. Plenum Press, New York.

- 1977. Genetics of cellular differentiation: Stable nuclear differentiation in eucaryotic unicells. Annu. Rev. Genet. 11: 349-367.
Sonneborn, T.M. and M.V. Schneller. 1979. A genetic system for alternative stable characteristics in genomically identical homozygous clones. Dev. Genet. 1: 21-46.

Steele, C.J., G.A. Barkocy-Gallagher, L.B. Preer, and J.R. Preer, Jr. 1994. Developmentally excised sequences in micronuclear DNA of Paramecium. Proc. Natl. Acad. Sci. 91: 22552259.

Williams, K., T.G. Doak, and G. Herrick. 1993. Developmental precise excision of Oxytricha trifallax telomere-bearing elements and formation of circles closed by a copy of the flanking target duplication. EMBO I. 12: 4593-4601.

You, Y., J. Scott, and J. Forney. 1994. The role of macronuclear DNA sequences in the permanent rescue of a non-Mendelian mutation in Paramecium tetraurelia. Genetics 136: 1319-1324. 


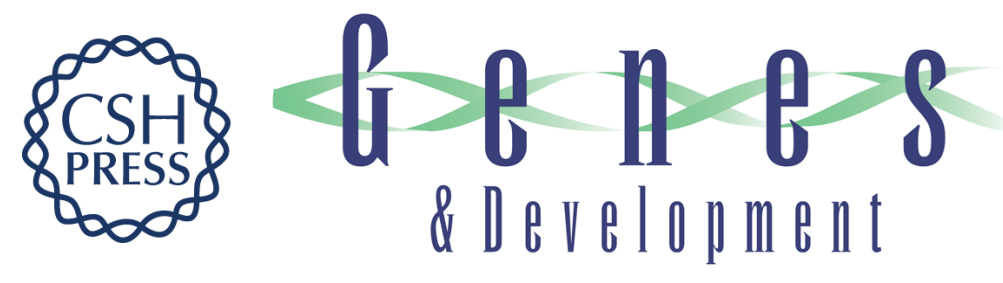

\section{Epigenetic self-regulation of developmental excision of an internal eliminated sequence on Paramecium tetraurelia.}

S Duharcourt, A Butler and E Meyer

Genes Dev. 1995, 9:

Access the most recent version at doi:10.1101/gad.9.16.2065

References This article cites 27 articles, 13 of which can be accessed free at: http://genesdev.cshlp.org/content/9/16/2065.full.html\#ref-list-1

License

Email Alerting Receive free email alerts when new articles cite this article - sign up in the box at the top Service right corner of the article or click here.

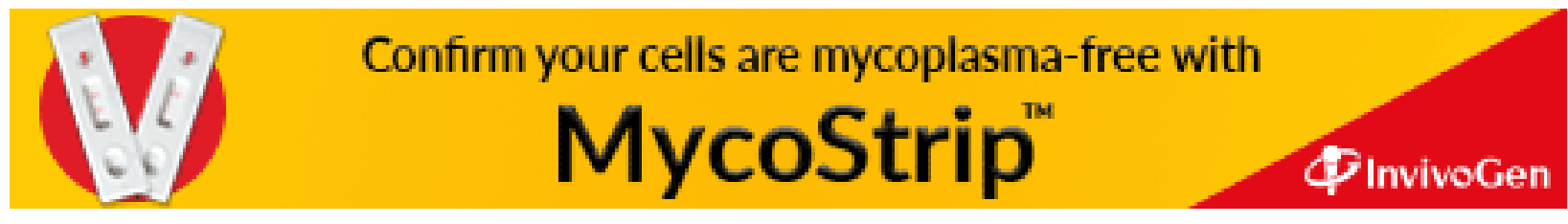

